\title{
BEHAVIOUR OF DUCTILE HOLLOW REINFORCED CONCRETE COLUMNS
}

\author{
J.B. Mander (i), M.J.N. Priestley (ii), and R.Park (iii)
}

This paper was presented at the Third South Pacific Regional

Conference on Earthquake Engineering, Wellington, May 1983

SYNOPSIS:

An experimental investigation into the seismic performance of ductile hollow reinforced concrete bridge piers is described. Four $3.2 \mathrm{~m}$ high specimens, $750 \mathrm{~mm}$ square with $120 \mathrm{~mm}$ thick walls containing 60 longitudinal steel bars and different arrangements of confining steel in the plastic hinge zone were subjected to a constant axial load and cyclic lateral displacements. An assessment of the effect of axial load and the amount of transverse steel on the rotational capacity of the plastic hinge is made. The specimens performed satisfactorily at member ductilities between 6 and 8 without any significant degradation of strength under cyclic loading.

\section{NOTATION :}

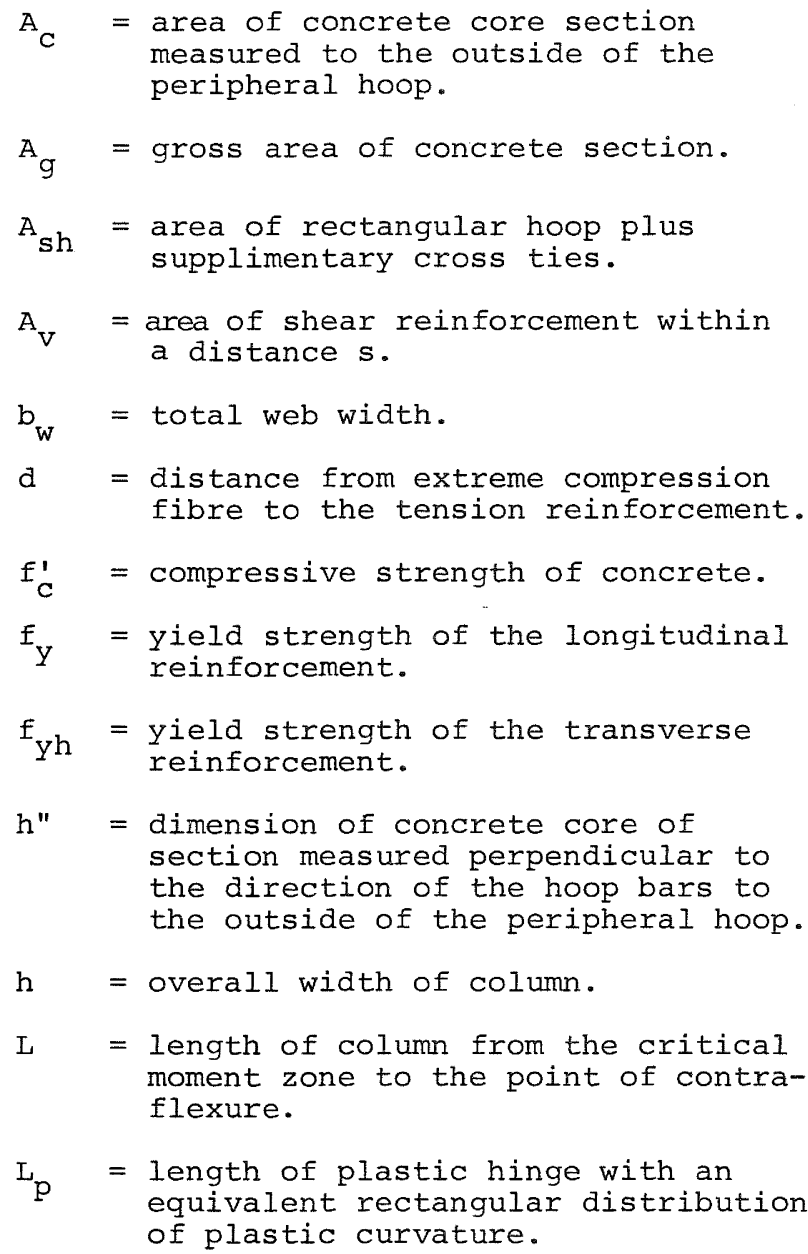
measured to the outside of the peripheral hoop.

$\mathrm{A}_{\mathrm{g}}=$ gross area of concrete section.

$\mathrm{A}_{\text {sh }}=$ area of rectangular hoop plus supplimentary cross ties.

$\mathrm{A}_{\mathrm{V}}=$ area of shear reinforcement within a distance $\mathbf{s}$.

$\mathrm{b}_{\mathrm{w}}=$ total web width.

d = distance from extreme compression fibre to the tension reinforcement.

$\mathrm{f}_{\mathrm{C}}^{\prime} \quad=$ compressive strength of concrete.

$\mathrm{f}_{\mathrm{y}}=$ yield strength of the longitudinal reinforcement.

$f_{y h}=$ yield strength of the transverse reinforcement.

$\mathrm{h}^{\prime} \quad$ = dimension of concrete core of section measured perpendicular to the direction of the hoop bars to the outside of the peripheral hoop.

$\mathrm{h}=$ overall width of column.

$\mathrm{L} \quad=$ length of column from the critical moment zone to the point of contraflexure.

$L_{p}=$ length of plastic hinge with an equivalent rectangular distribution of plastic curvature.

(i) Graduate Student, University of Canterbury, Christchurch, New Zealand, and Civil Engineer with New Zealand Railways Corporation.

(ii) Reader in Civil Engineering, University of Canterbury, Christchurch, New Zealand.

(iii) Professor and Head of Department of Civil Engineering, University of Canterbury, Christchurch, New Zealand.

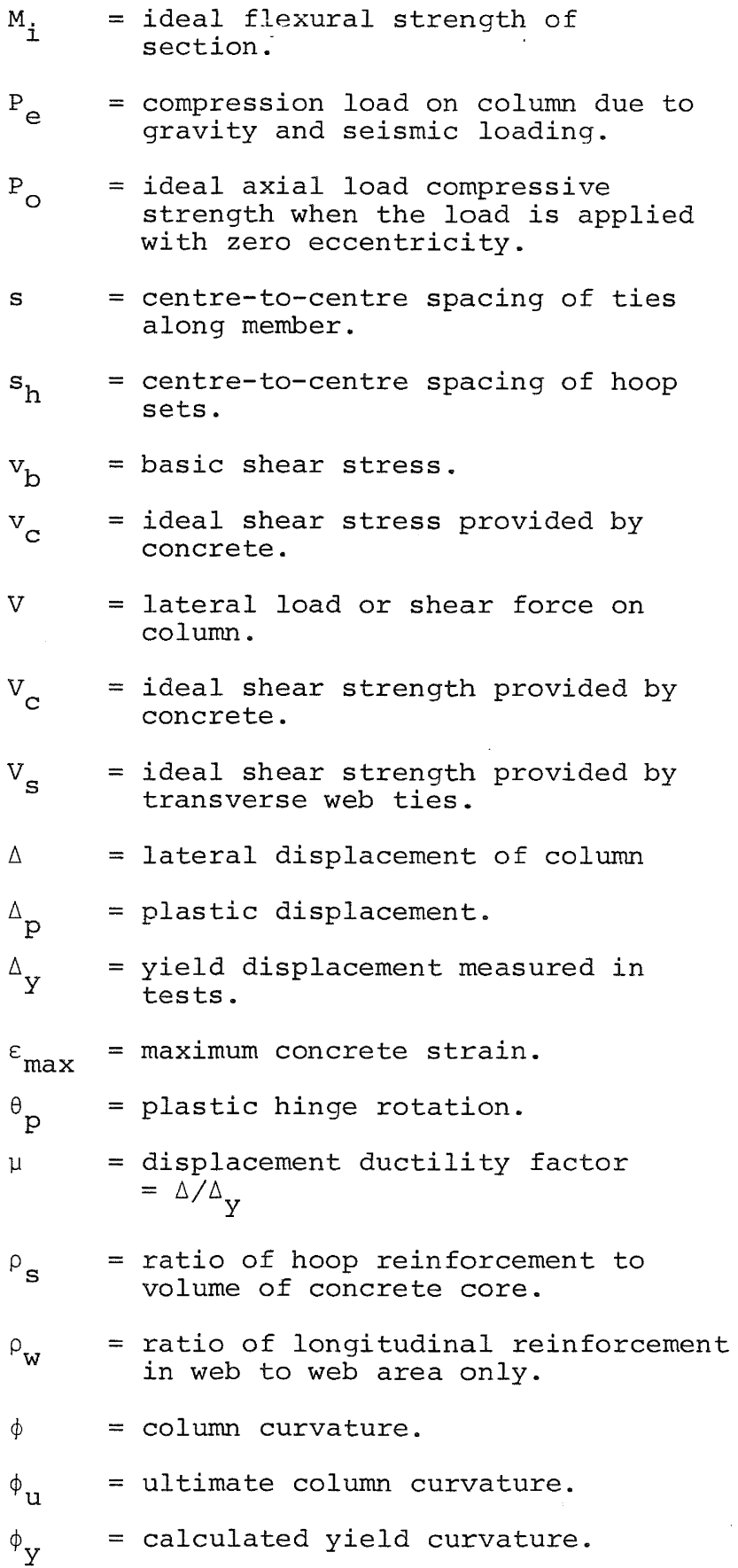




\section{INTRODUCTION :}

The construction of tall bridge piers using rectangular hollow columns is an attractive means by which the superstructure weight, and hence seismic loading, is minimised whilst maintaining column strength, and significantly reducing the construction cost. However, currently there is a reluctance amongst bridge designers to specify the use of ductile hollow columns for tall bridge piers, due to the unknown performance of the plastic hinge zone under severe seismic disturbances. In New Zealand to date, bridge structures built with hollow piers have been designed either for a high base shear and limited ductility or with nonductile stepping (rocking) foundations. Examples of these two design approaches are the Boundary Road Bridge, Hamilton, and the South Rangitekei Rail Bridge, respectively.

Current design philosophy (1) for ductile reinforced concrete columns aims at providing sufficient transverse steel in potential plastic hinge regions to confine the compressed concrete, prevent lateral buckling of the longitudinal reinforcing steel, and act as shear reinforcements. The research described in this paper was an experimental investigation of the quantity of confining steel required for ductility of rectangular hollow columns in seismic design. Full details of the study summarised in this paper may be seen reported elsewhere (2).

\section{TRANSVERSE REINFORCEMENT REQUIREMENTS :}

The New Zealand Code of Practice for the design of concrete structures NZS 3101 (1) requires that in potential plastic hinge regions of columns the total effective steel area, $A_{s h}$, of rectangular hoops plus supplementary cross ties, if any, for rectangular members in the direction under consideration the centreto-centre spacing, $s_{h}$, should not be less than

$$
A_{s h}=0.3 s_{h} h^{\prime \prime}\left(\frac{A_{g}}{A_{C}}-1\right) \frac{f_{C}^{\prime}}{f_{y h}}\left(\begin{array}{l}
0.5+1.25 \\
\frac{P_{e}}{\phi f_{C}^{\prime} A_{g}}
\end{array}\right)
$$

or

$$
A_{s h}=0.12 s_{h} h^{\prime \prime} \frac{f_{c}^{\prime}}{f_{y h}}\left(0.5+1.25 \frac{P_{e}}{\phi f_{c}^{\prime} A_{g}}\right)
$$

whichever is greater, in which $P_{e}$ is not permitted to exceed the larger of $\phi 0.7$ ${ }_{C}^{\prime}{ }^{A} g$ or $\phi 0.7 \mathrm{P}_{\circ} ;$ and where $\phi=1.0$ if the column design actions are such to provide a high degree of protection against plastic hinging of the column, otherwise $\phi=0.90$. In plastic hinge regions, the yield force of the transverse steel should not be less than one-sixteenth of the yield force of the longitudinal bar it is to restrain. Also, the centre-to-centre spacing of

hoopsets should not exceed the smaller of:

(i) one fifth of the smaller section dimension

(ii) $200 \mathrm{~mm}$

(iii) six times the diameter of the longitudinal bar to be restrained

(iv) the spacing between cross-linked longitudinal bars should not exceed $200 \mathrm{~mm}$.

The length of the potential plastic hinge region when $\mathrm{P}_{\mathrm{e}} \leqq \phi 0.3 \mathrm{f}_{\mathrm{C}}^{\prime} \mathrm{A} g$. This modification accounts for the greater spread of plasticity along the column at higher levels of axial load. Such spread occurs due to the strength enhancement of confined concrete and thus flexural strength, in the more heavily confined end regions, in which the moment capacity is reached adjacent to the region of plastification.

It should be noted that the above code provisions are for the design and detailing of solid reinforced concrete members that may be subjected to the yielding under the action of a design earthquake. Furthermore solid reinforced concrete members designed in accordance with these provisions may be assumed to have an available member displacement ductility factor of eight (3).

In New Zealand, a bridge designer may choose a structure ductility between one (for an elastically responding structure) and six (for a fully ductile structure) $(3,4)$. The detailing of both fully ductile $(\mu=6)$ and partially ductile $(1<\mu<6)$ piers must be in accordance with the above code provisions. However this detailing may result in unnecessary congestion of transverse reinforcement, particularly in structures of limited ductility (say $\mu<4$ ). For such structures it is suggested that in the potential plastic hinge region a reduction factor be applied to the transverse steel area calculated by Eqs. 1 and 2 .

The ductility demand of column members can be deterministically assessed by either one or both of:

(a) an elasto-plastic limit analysis in which the ductility demand of members can be estimated from a collapse mechanism, and a knowledge of the required structural displacement ductility factor;

(b) dynamic time-history analyses using selected earthquake ground motions.

On the basis of numerous experimental test results it has been shown that a member ductility capacity of at least $\mu=8$ should be obtainable for columns with standard code (1) transverse reinforcement detailing given by the most critical of Eqs. I or 2. For the design of columns with a limited member ductility 
demand, it is proposed that the attainable member ductility capacity will be not less than

$\mu=2+6 \mathrm{~A}_{\mathrm{sh}}\left(\right.$ provided) $/ \mathrm{A}_{\mathrm{sh}}$ (code)

where $A_{\text {sh }}$ (code) is the transverse steel area required by NZS 3101 (1) and $A_{\text {sh }}$ (provided) is the transverse steel area provided in the design. It will be noted that Eq. 3 implies a member ductility of at least two if no confinement reinforcement is provided. This can be justified on the basis that the concrete crushing strain of at least 0.004 is greater than twice the yield strain $(0.0014$ to 0.002$)$.

One of the objectives of the hollow column tests in this test programme was to determine the applicability of the confinement provisions of NZS 3101 (1) together with the above modification suggested for members which require only limited ductility.

The above empirical approach should give a lower bound solution for the ductility capacity of a column member. A more rational approach would be to use momentcurvature analyses for the hollow column members under combined axial load and cyclic flexure to determine the hysteretic performance. This deterministic approach is described in Ref. 2.

\section{DESCRIPTION OF TEST UNITS:}

Four hollow column test units were constructed, all with the same dimensions as shown in Fig. 1. The test units are designated as Columns A, B, C and D. Each test unit had a total height of $3.9 \mathrm{~m}$ a $750 \mathrm{~mm}$ square cross section and $120 \mathrm{~mm}$ thick walls. The longitudinal reinforcement consisted of sixty $10 \mathrm{~mm}$ diameter Grade 275 deformed bars, equally spaced about both the internal and external faces of hollow column to give a steel ratio of 1.55\%. The transverse hoop steel was from $6 \mathrm{~mm}$ diameter Grade 275 plain round bars. The test units are $40 \%$ scale models of a $1900 \mathrm{~mm}$ prototype square hollow column with $300 \mathrm{~mm}$ thick walls. The choice of a relatively large-scale test unit meant that ordinary reinforcing bars together with normal (unscaled) concrete could be used in the construction.

The general set up of the test rig and hollow column is illustrated in Fig. 2 . A $10 \mathrm{MN}$ capacity DARTEC universal testing machine was used to apply the compressive axial load to the column specimen. The loading frame was bolted to the solid concrete base of the test unit. A $500 \mathrm{kN}$ capacity double acting MTS servo-hydraulic loading jack was used to apply a lateral load between the top of the cantilever arm of the loading frame and the top of the hollow column. Hence, bending moment, shear force and axial load were applied to the member, with the critical section being located just above the base. The jack displacements could be applied cyclically to reverse the direction of lateral load and hence to reverse the moment and shear. For the dimensions shown in Fig. 2, the hollow columns had an aspect ratio of
$\mathrm{L} / \mathrm{h}=3200 / 750=4.27$, where $\mathrm{L}$ is the height of the column from the critical section to the point of contraflexure and $h$ is the overall depth of the hollow column unit.

The concrete pouring seouence for the hollow columns together with the compressive cylinder strengths measured at 28 days and at time of testing the units are shown in Fig. 3. Details of the mix specifications are given in Fig. 1. The stress-strain curves together with the strength parameters of the reinforcing steel are presented in Fig. 3.

Note that for the purpose of strength and deformation calculations of the hollow columns, the concrete strength was assumed to be $\mathrm{F}_{\mathrm{C}}^{\prime}=30 \mathrm{MPa}$ for columns. $A$ and $B, f_{C}^{\prime}=29 \mathrm{MPa}$ for Columns $C$ and $D$, and steel strengths of $\mathrm{f}_{\mathrm{y}}=335 \mathrm{MPa}$ and $f_{g h}=320 \mathrm{MPa}$ were used for the longitudinal and transverse reinforcement, respectively. In the calculations for ideal flexural and shear strength it was assumed that the concrete strength was the measured unconfined value ( $i . e$. the above $f_{c}^{\prime}$ value was used) and the steel strength was measured yield strength (i.e. no allowance for strain hardening was made).

The main variables during the tests were the level of axial load applied to the specimen, $\mathrm{P}$, and the corresponding amount of transverse reinforcement present in the plastic hinge region. The applied axial load level, as expressed by the ratio $\mathrm{P}_{\mathrm{f}} / \mathrm{f}^{\prime} \mathrm{A}$, was $0.1,0.5,0.3$ and 0.3 for $\mathrm{e}^{\prime} \mathrm{C} \mathrm{g}^{\prime}$ Columns $\mathrm{A}, \mathrm{B}, \mathrm{C}$, and $\mathrm{D}$, respectively. Interaction diagrams for the hollow columns together with the ideal column strengths based on the measured material properties are presented in Fig. 4. The centre-to-centre spacing of the hoop sets was $60 \mathrm{~mm}, 30 \mathrm{~mm}$, $40 \mathrm{~mm}$ and $60 \mathrm{~mm}$ for Columns $\mathrm{A}, \mathrm{B}, \mathrm{C}$ and $D$, respectively. The actual quantities of rectangular hoop reinforcement present in Columns $A, B, C$ and $D$ were 0.74 , $0.83,0.83$ and 0.55 times that required by the most critical of Eqs. 1 and 2 , respectively. In this calculation using Eqs. 1 and 2 the strength reduction factor, $\phi$, was assumed to be unity.

\section{INSTRUMENTATION:}

Longitudinal strains and curvatures within the plastic hinge zone were measured by linear potentiometers attached to $12 \mathrm{~mm}$ diameter rods which passed through, and were bonded to, the core concrete of the hollow column webs. These potentiometers measured the hollow column deformations, above the solid concrete base, over five sequential gauge lengths of $80,120,200,300$, and $500 \mathrm{~mm}$ in the plane of lateral loading. The lateral displacement at the tip of the hollow column, relative to the solid concrete base, was measured using a $300 \mathrm{~mm}$ travel linear potentiometer as shown in Fig. 2. Electrical resistance strain gauges were attached at various locations on the transverse reinforcement within the plastic hinge region. Gauges were fixed to cross ties legs of the small 


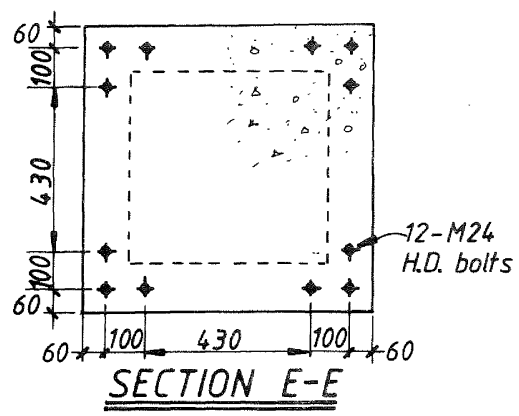

\begin{tabular}{|l|c|c|c|}
\cline { 2 - 4 } & \multicolumn{3}{|c|}{ CONCRETE MIX DETAILS } \\
\cline { 2 - 4 } & $\begin{array}{c}\text { 28 doy target } \\
\text { Strength (MPa) }\end{array}$ & $\begin{array}{c}\text { Aggregate } \\
\text { size }(\mathrm{mm})\end{array}$ & $\begin{array}{c}\text { Slump } \\
(\mathrm{mm})\end{array}$ \\
\hline Base & 40 & 20 & 75 \\
Column & 25 & 13 & 150 \\
\hline
\end{tabular}

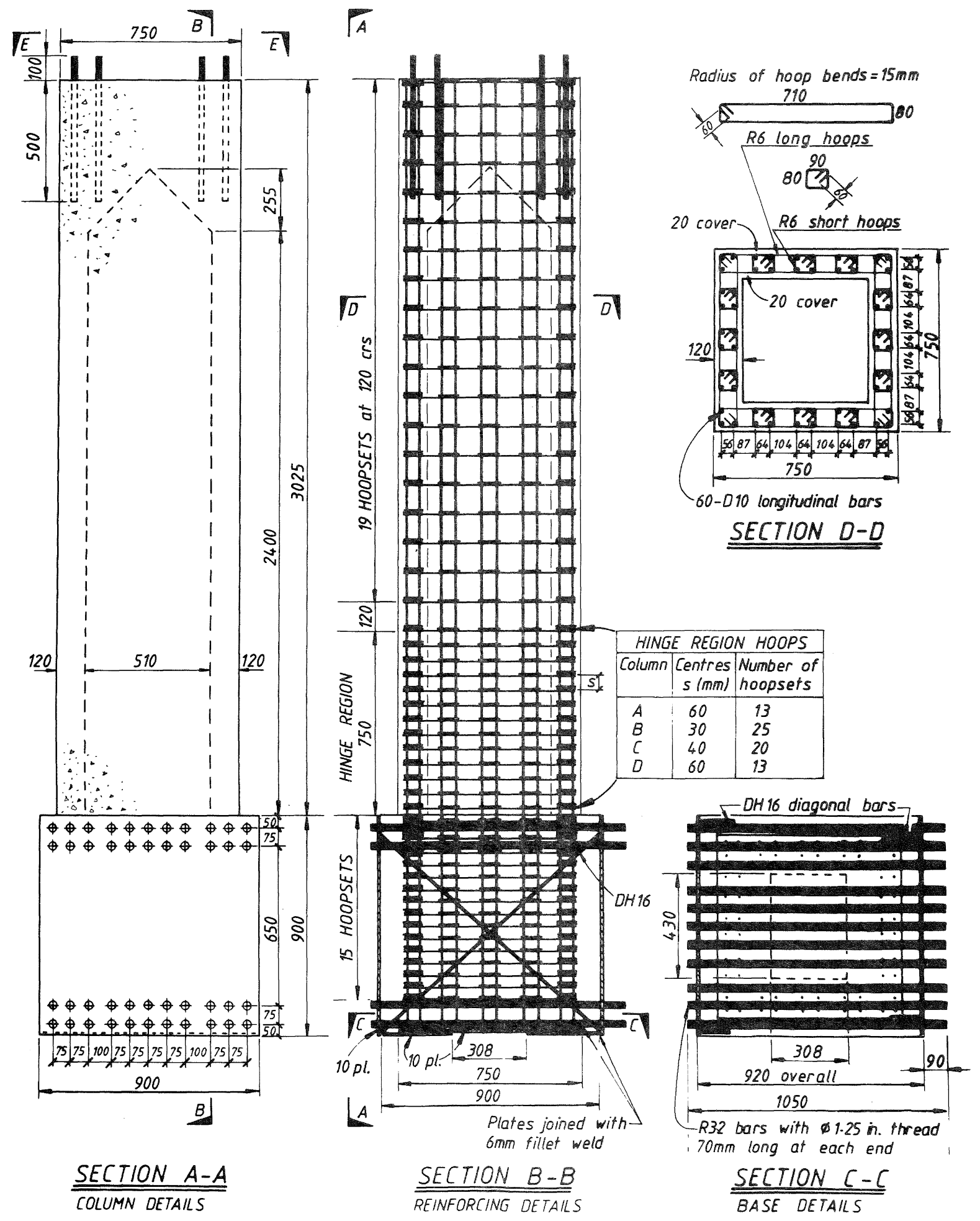

FIG. 1 : COLUMN CONSTRUCTION DETAILS 


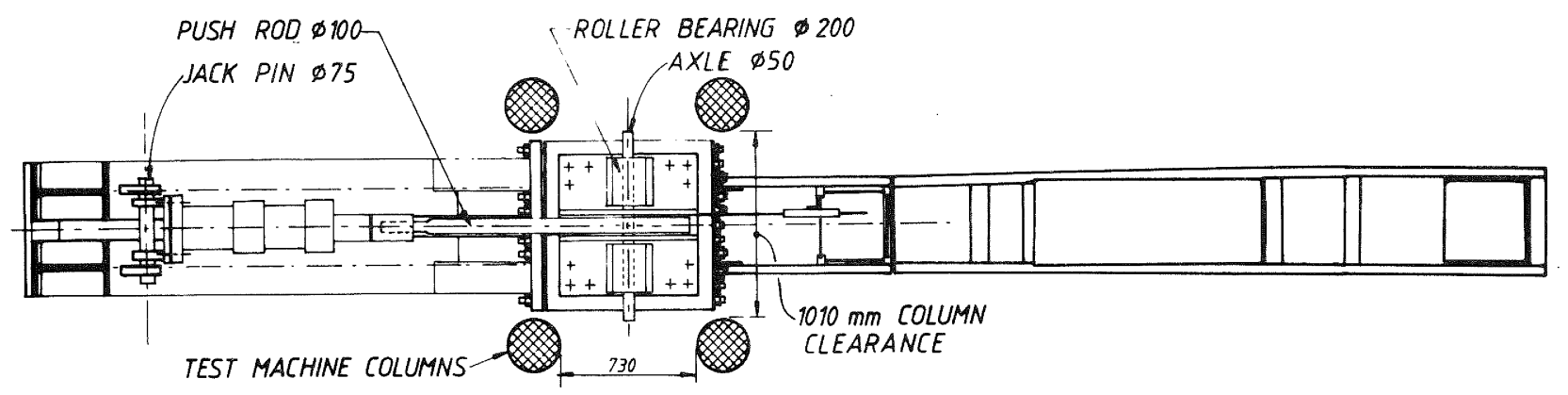

PLAN [THROUGH A-A]

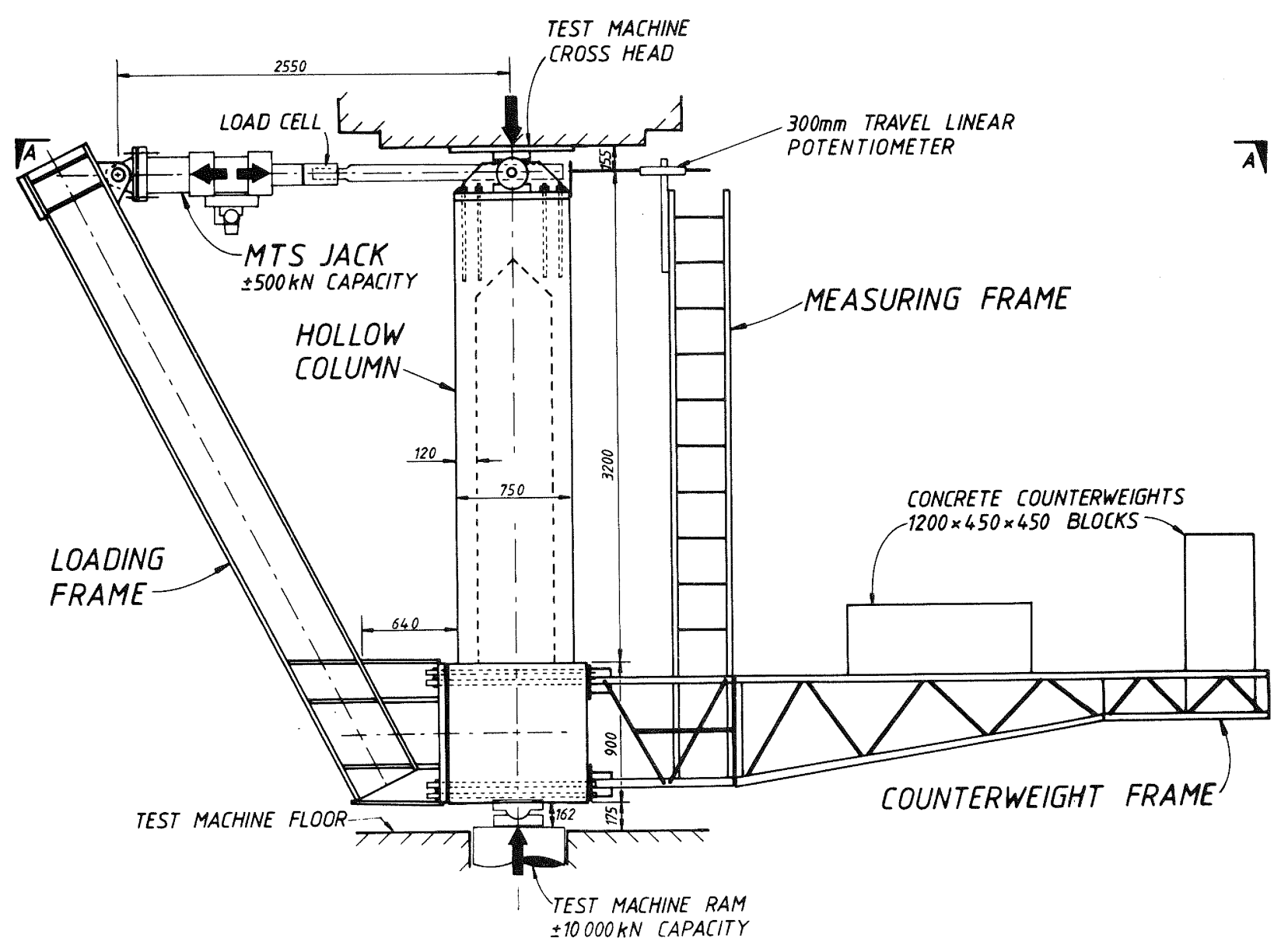

ELEVATION

FIG. 2 : SET UP OF TEST RIG AND HOLLOW COLUMN 


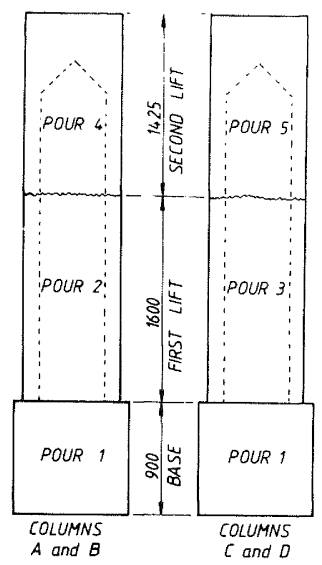

\begin{tabular}{|c|c|c|}
\hline POUR & $\begin{array}{c}\text { CONCRETE } \\
\text { STRENGH } \\
\text { AT } \\
28 \text { DAYS } \\
\text { (MPa) }\end{array}$ & $\begin{array}{c}\text { CONCRETE } \\
\text { STRENGTH } \\
\text { AT } \\
\text { IESING } \\
\text { (MPa) }\end{array}$ \\
\hline 1 & 37 & 40 \\
2 & 26 & 30 \\
3 & 27 & 29 \\
4 & 29 & 32 \\
5 & 24 & 26 \\
\hline
\end{tabular}

(a) CONCRETE POURING SEQUENCE AND STRENGTHS

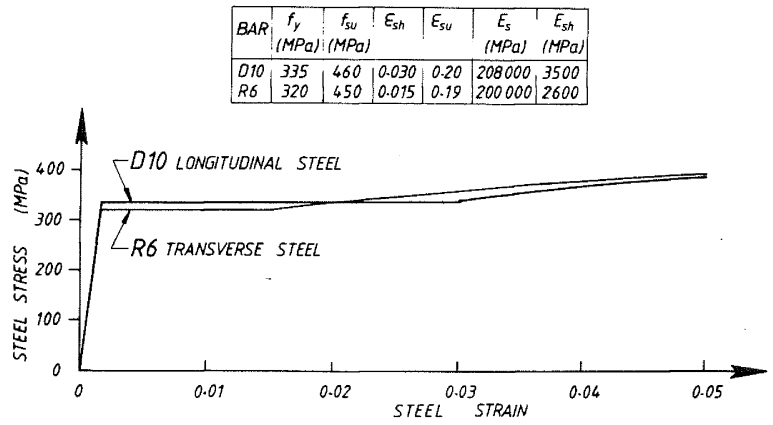

(b) STRESS - STRAIN CURVES FOR REINFORCING STEEL

FIG. 3 : DETAILS OF MATERIAL PROPERTIES.

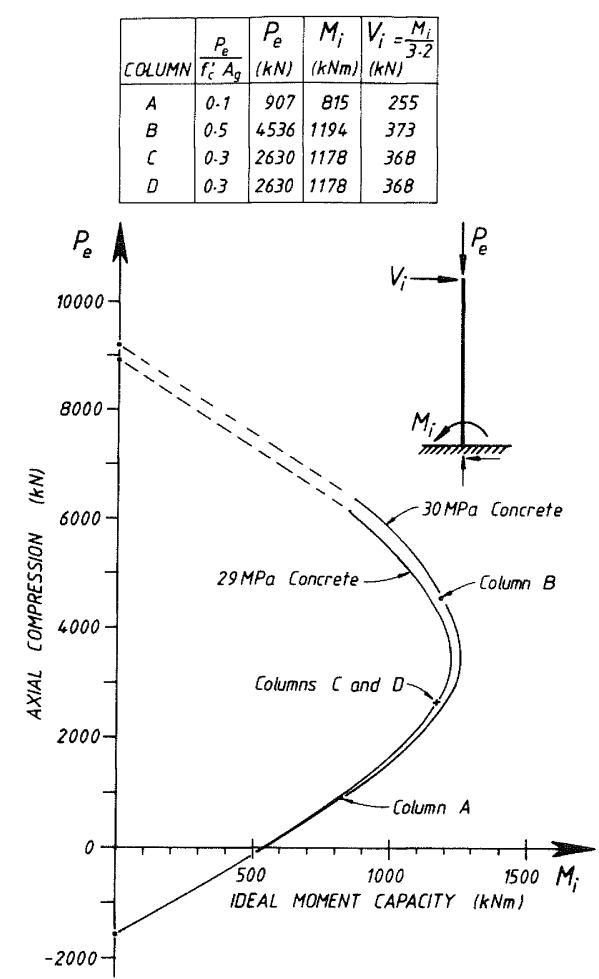

FIG. 4 : INTERACTION DIAGRAM FOR HOLLOW COLUMNS 
hoops in the column flanges to observe the steel strains due to the confinement of the concrete. Strains resulting from shear in the column were measured by gauges attached to the long rectangular hoops in the web.

\section{LOAD SEQUENCES:}

An initial lateral load cycle to approximately $75 \%$ of the ideal column strength was applied in both the positive and negative directions. From the resulting lateral load-displacement graph, an experimental value for the yield displacement, $\Delta_{y}$ ' was obtained by extrapolating a straight line from the origin through the peak lateral load-displacement coordinate to the lateral load at ideal strength, $v_{i}$. Subsequent testing in a quasi-static fashion, consisted of two complete cycles to displacement ductility factors each of $\mu= \pm 2, \pm 4, \pm 6$ and +8 , unless premature failure of the specimen caused a halt to the test programme.

\section{EXPERIMENTAL RESULTS:}

Deflection Behaviour: Lateral loaddisplacement hysteresis loops are presented in Fig. 5 for Columns A - D. Included in each figure are photographs of the state of each unit at the completion of the quasi-static testing with the loose cover removed to show the extent of spalling. Superimposed on the measured lateral load-displacement curves of these figures is the ideal lateral load capacity of the specimen plotted as a dashed line. Note that the lines drop as the displacement increases owing to the secondary $\mathrm{P}$-delta moment effect of the axial load. Where the axial load level is high, for example Column $\mathrm{B}$ where $\mathrm{P}_{e}=0.5 \mathrm{f}_{\mathrm{C}}^{\prime} \mathrm{A}_{\mathrm{g}}$, the secondary moments from the P-delta effect become more significant.

The hysteresis loops show very good energy dissipating characteristics and stability. With increasing displacement ductility, some stiffness degradation of the loading curves is apparent. Very little degradation of strength occurs on the second complete cycle at constant ductility factors.

Column $A: \mathrm{P}_{e}=0.1 \mathrm{f}_{\mathrm{C}}^{\prime} \mathrm{A}_{\mathrm{g}}$

This specimen was provided with a minimum amount of transverse reinforcement in the plastic hinge zone. The amount was governed by the spacing of transverse steel required to prevent buckling of the longitudinal steel, and a spacing of six longitudinal bar diameters was used as recommended in the code (1).

The low level of axial load applied to the specimen throughout testing was intended to represent an average level of load expected on a prototype pier. Note that the transverse steel in the hinge zone was equal to only $74 \%$ of the amount required by the most critical of Eqs. 1 and 2. At the completion of quasi-static testing (at $\mu=+8$ ) the concrete cover had spalled over a height of $150 \mathrm{~mm}$ above the solid concrete base. Buckling of the four external corner longitudinal bars had commenced. Nevertheless, the lateral load at a displacement uctility of \pm 8 was still $10 \%$ in excess of the ideal strength, and increasing. There was little degradation of column strength due to cyclic loading. The testing of column A was concluded by dynamic cyclic loading at a period of 7.5 seconds per cycle at a displacement ductility factor of +4 . After 40 cycles some of the longitudinal bars fractured and the test was terminated. However, up to this stage there was still little sign of strength degradation.

Column B: $\mathrm{P}_{\mathrm{e}}=0.5 \mathrm{f}_{\mathrm{C}}^{\prime} \mathrm{A}_{g}$

The plastic hinge region for column $B$ was designed and detailed in accordance with the Code (1) requirements for full ductility for an axial load level of

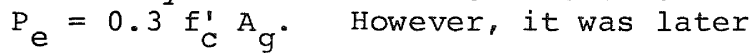
decided to test the specimen simulating severe seismic overload conditions with an axial load of $\mathrm{P}_{e}=0.5 \mathrm{f}_{\mathrm{c}}^{\prime} \mathrm{A}_{g}$.

Consequently the column suffered a premature failure resulting from a spread of compression steel yield to above the extent of confinement due to the high overstrength of the confined hinge zone. A maximum lateral load $38 \%$ above the ideal column strength was carried at a displacement ductility factor of +3.3 . At this stage, incipient buckling took place in the outside layer of the longitudinal compression steel in the column flange. The buckling occurred just above the confinement plastic hinge zone, approximately $800 \mathrm{~mm}$ above the base of the column, where the spacing of the transverse hoops was twelve longitudinal bar diameters. It is evident that the high moment demand ( $1.05 \mathrm{M}_{j}$ ) at this location above the confined plastic hinge zone, requiring compressive steel strains in excess of the yield strain $(0.0016)$, together with inadequate transverse restraint, eventually led to buckling of the longitudinal bars. Subsequently as the lateral displacements were increased, the cover concrete spalled due to substantial buckling of the longitudinal bars. Hence the compressive load capacity of the flange was significantly reduced, resulting in failure of the hollow column. Nonetheless, the plastic hinge region performed well, even though only $83 \%$ of the transverse steel required by the most critical of Eqs. 1 and 2 was provided.

$$
\text { Columns } C \text { and } D: P_{e}=0.3 f_{C}^{\prime} A_{g}
$$

The intensity of axial load applied to Columns $C$ and $D$ was intended to represent the maximum level expected in the design of hollow columns for prototype bridge piers. Column $C$ was provided with the same proportion of transverse steel as Column B - 83\% of the amount required by the most critical of Eqs. I and 2. As in Column $A$, the maximum centre-to-centre hoopset spacing of six longitudinal bar diameters was used for Column $D$, thus providing $55 \%$ of the transverse steel required by the most critical of Eqs. 1 and 2. Both Columns 

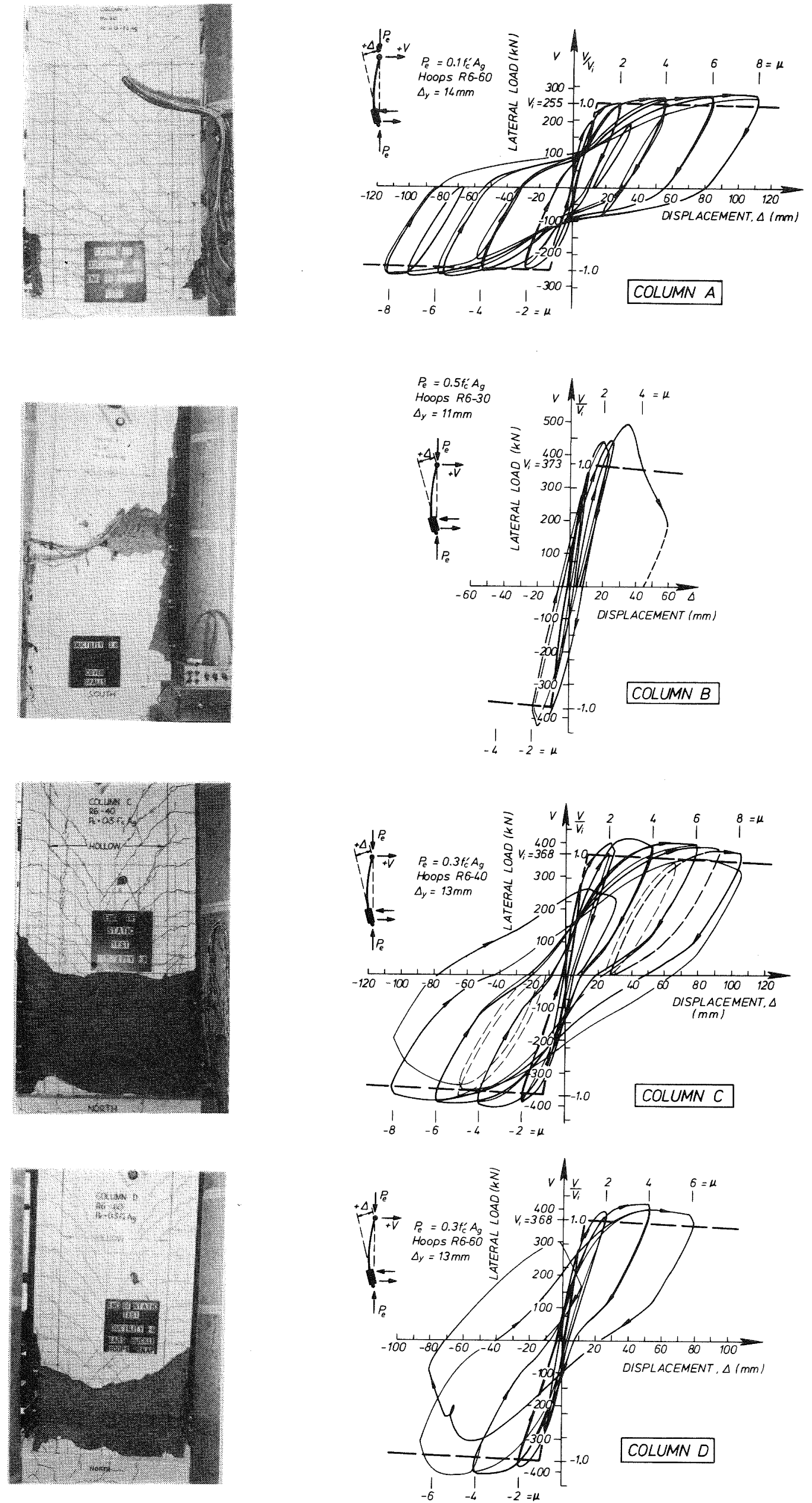

FIG. 5 : LATERAL LOAD-DISPLACEMENT HYSTERESIS LOOPS. 
$C$ and D performed well under cyclic loading with the lateral load between 10 and 15\% in excess of the ideal column strength. Column $C$ eventually suffered a confinement failure when a number of the small transverse flange hoops fractured about $250 \mathrm{~mm}$ above the column base on the final quasi-static load cycle at $\mu=-8$. Column $\mathrm{D}$ behaved in a similar manner to Column $C$ up to $\mu=+4$. However, due to the reduced level of confinement, the failure of column $D$ occurred earlier than for column C. Fracture of some of the small transverse flange hoops, $270 \mathrm{~mm}$ above the column base, occurred as the displacement was increased from $\mu=-5.8$ to $\mu=-6.5$.

Some "pinching" of the loaddisplacement hysteresis loops is apparent for Columns $C$ and $D\left(P_{e}=0.3 f_{C}^{\prime} A_{g}\right)$ and particularly Column $A(P=0.1$ $\mathrm{f}_{\mathrm{C}}^{\prime} \mathrm{A}_{\mathrm{g}}$ ). Pinching is a charăcteristic of hysteresis loops for columns with low to medium levels of axial load. Pinching is due to the compressive axial load causing the closure of open cracks in the compressed flange. The open cracks remain from the tensile extension of the steel which occurred from the cycle of loading in the previous direction. Note the absence of pinching for Column $B$ which had the relatively high axial load ratio $\mathrm{P}_{\mathrm{e}} / \mathrm{f}_{\mathrm{C}}^{\prime A} \mathrm{~A}$ of 0.5 .

Pinching of hysteresis loops can also arise in beams and squat members due to sliding shear deformation in the plastic hinge region. Such deformation can be detected visually at transverse cracks where longitudinal grid lines marked on the face of the column are displaced laterally on each side of the confined crack. For the hollow columns tested therein, there was no observed lateral displacement of the longitudinal grid lines and cracks. Thus it was evident that sliding shear did not contribute significantly to the deformations of the hollow columns. As mentioned above, the column failure was flexurally dominated, resulting from either a loss of confinement in the flange concrete (Columns B, C and D) or low cycle fatigue of the longitudinal reinforcement.

Curvature Distribution: Curvature profiles for the hollow column specimens plotted at successive displacement ductility factor peaks of $\mu= \pm 2, \pm 4, \pm 6$ and +8 are presented in Fig. 6 . The àverage curvature values have been plotted at the mid-point of the successive gauge lengths and joined by straight lines.

As the bending moment increased, from zero at the top of the specimen to a maximum at the base of the hollow column, the curvature increased. At the onset of plasticity, when the bending moment exceeded the yield moment, the curvature profile became non-linear. Thus the general trend for the curvature profiles was an increase in curvature as the displacement ductility increased, and an increase in curvature as the applied bending moment increased. Note however, that there does not appear to be a tendency for the plasticity to spread as the ductility factor increases. Some irregularity of the curvature profiles existed due to the random nature of the flexural crack formation. This non-symmetrical feature of some curvature distributions for the forward and reverse loadings (especially in Columns $C$ and $D$ ) indicates that failure occurred at different heights of the two column flanges.

An equivalent plastic hinge length, $L_{p}$, may be found from the plastic displacement, $\Delta_{p}$, by taking the first moment of area of an idealised rectangular distribution of plastic curvature about the top of the member

$\Delta_{p}=(\mu-1) \Delta_{y}=\left(\phi_{u}-\phi_{y}\right) L_{p}\left(L-0.5 \cdot L_{p}\right)$

in which $\left(\phi_{\mathrm{u}}-\phi_{\mathrm{y}}\right)$ is the plastic curvature measured beyond the first yield curvature over the $80 \mathrm{~mm}$ gauge length adjacent to the solid concrete base, and $L$ is the distance from the critical section to the point of contraflexure $(3200 \mathrm{~mm})$. By rearranging $\mathrm{Eq}$. 4 it can be shown that

$\frac{L_{p}}{h}=\frac{L}{h}\left(1-\sqrt{\frac{1-2(\mu-1) \Delta_{y} / L^{2}}{\left(\phi_{u}-\phi_{y}\right)}}\right)$

where $\mathrm{h}$ is the overall depth of the column member $(750 \mathrm{~mm})$. Average experimental curvatures $\left(\phi_{u}\right)$ measured at displacement ductility peaks were used to calculate the non-dimensional equivalent plastic hinge lengths given by the above expression. Table 1 lists the results of $\mu=2,4,6$ and 8 . The experimentally measured equivalent plastic hinge lengths are comparatively insensitive to both the level of axial load and ductility (providing $|\mu| \geqq 4$ ), and have arange of $0.36 \mathrm{~h}$ to $0.41 \overline{\mathrm{h}}$.

For each specimen Table 2 lists the experimental member ductility demand obtained prior to column failure, together with the predicted member ductility capacity given by Eq. 3. The experimental results for columns $A, C$ and $D$ show that hollow columns are capable of sustaining member ductilities which are not less than the predicted capacity based on $\mathrm{Eq}$. 3 .

Also listed in Table 2 are values for the experimental plastic hinge rotation calculated from the expression

$\theta_{p}=\Delta_{p} /\left(L-0.5 L_{p}\right)$

in which $\Delta_{p}$ is the plastic displacement measured either at the end of quasistatic testing (Columns $A$ and $B$ ) or at first hoop fracture of the flange hoops. The equivalent plastic hinge length $\left(I_{p}\right)$ in Eq. 6 was taken as the final value obtained for each specimen in Table 1 , with $L=3200 \mathrm{~mm}$ and $\mathrm{h}=750 \mathrm{~mm}$. 

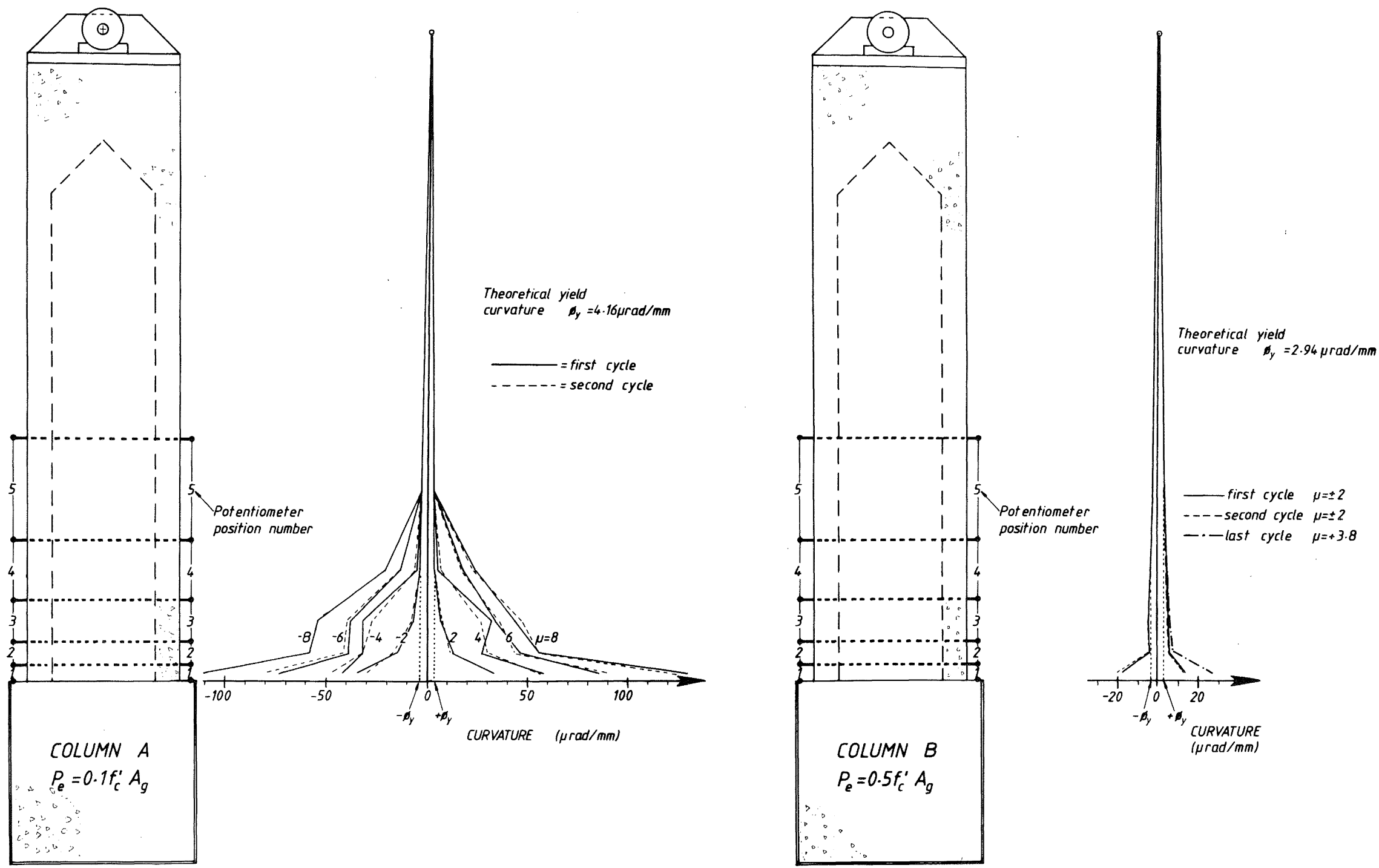

(a) Colunin is

(b) Colunn B

FIG. 6 : MEASURED CURVATURE PROFILES FOR THE FOUR TEST UNITS. 


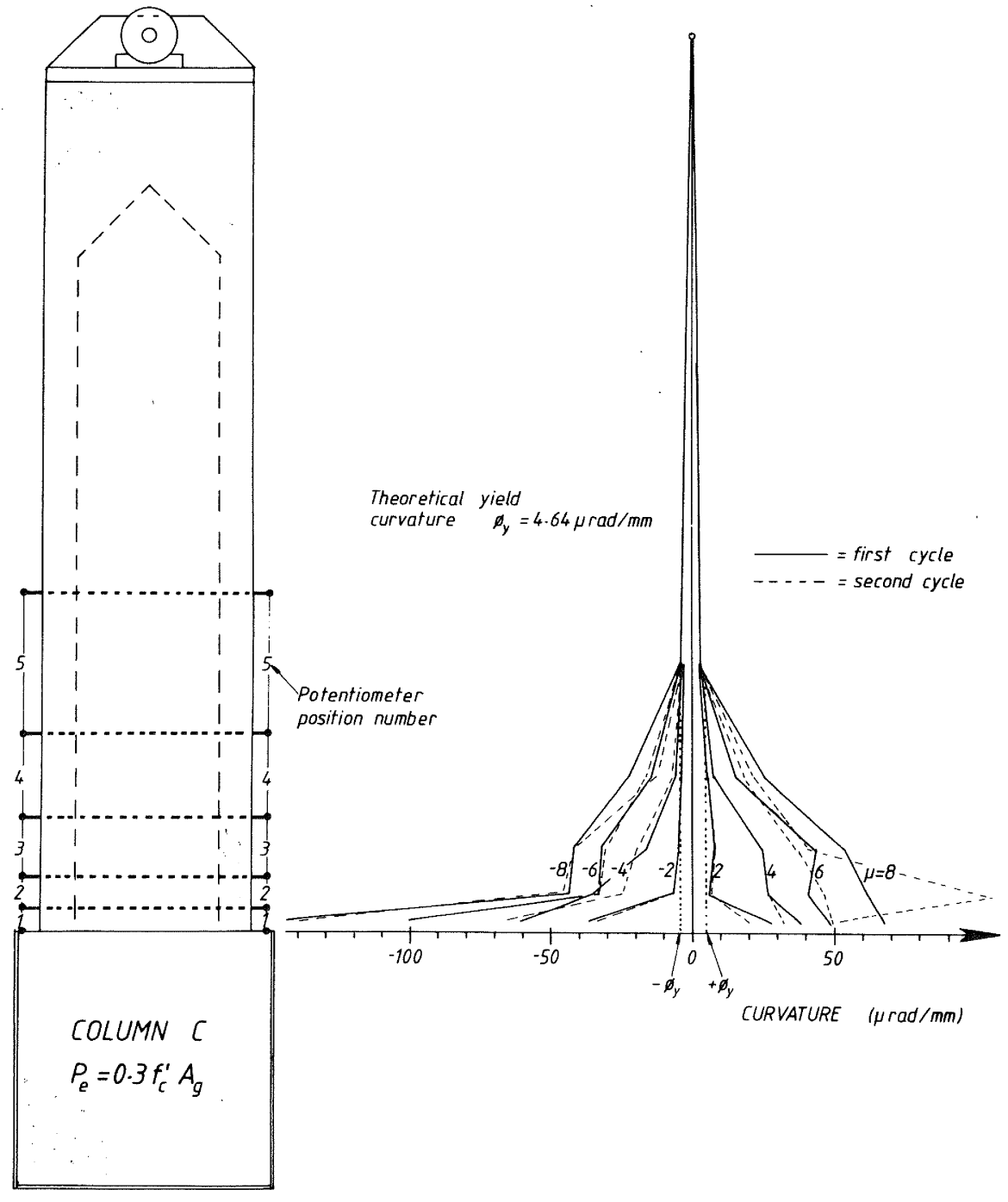

(c) Column $\mathrm{C}$

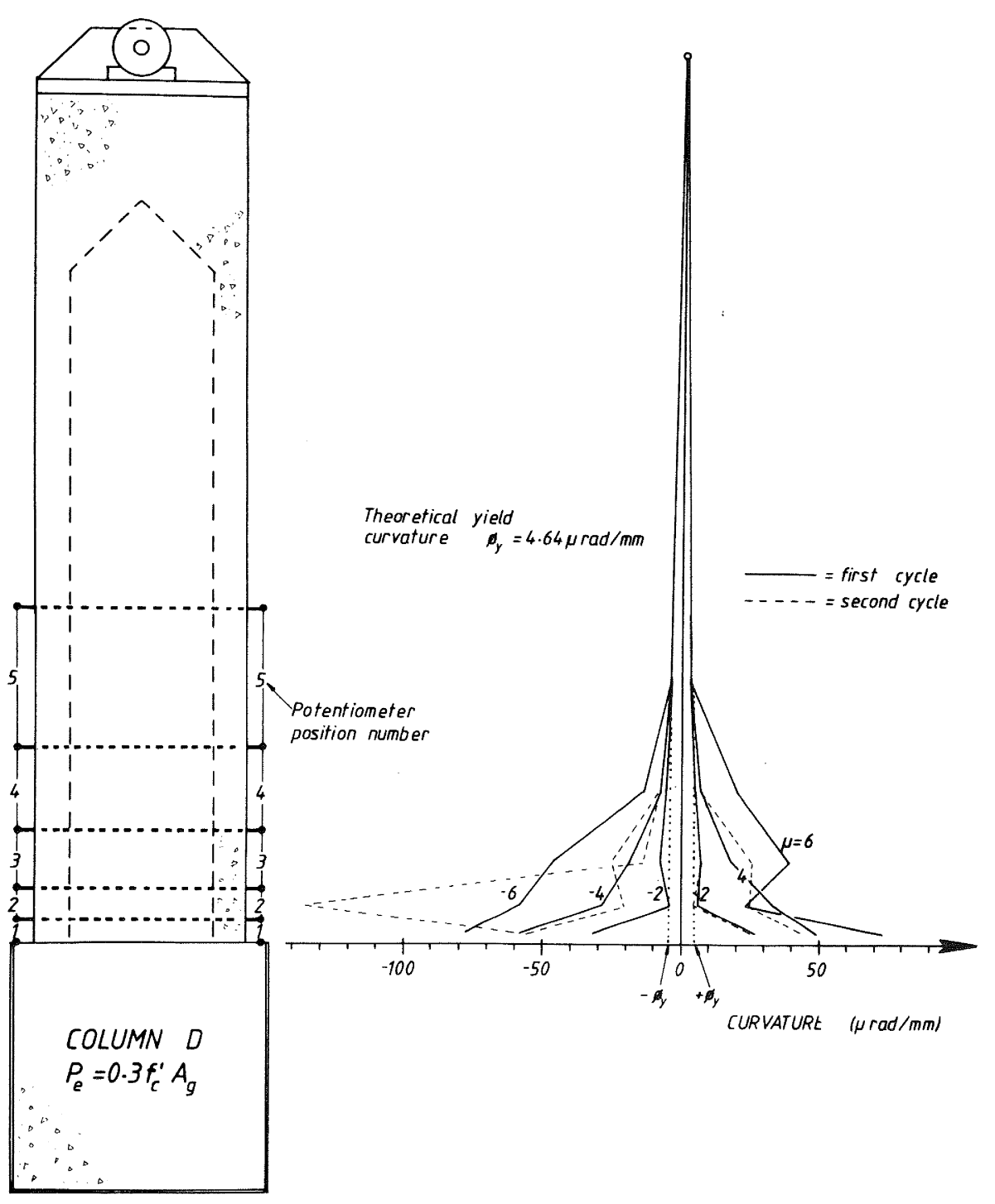

(d) Colunn D

FIG. 6 (CTD) : MEASURED CURVATURE PROFILES FOR THE FOUR TEST UNITS. 
obtained from Eq. 6 it is proposed that the attainable rotational capacity of column hinges will be not less than

$\theta_{p}=0.035 \mathrm{~A}_{s h}$ (provided) $/ \mathrm{A}_{\mathrm{sh}}$ (code) radians

This expression implies that a rotational capacity of at least 0.035 radians should be available for column hinges with standard code (I) detailing. Table 2 lists the predicted rotational capacity given by Eq. 7. Thus for the design of ductile structures, Eq. 7 could be used to indicate the available plastic rotation of column hinges.

Flange Strains: Profiles of the longitudinal compressive strain at the extreme compression fibre of the core concrete together with the transverse tensile strain in the small flange hoops is presented in Fig. 7. These strain profiles were measured in the flanges of the hollow columns during the quasi-static testing, at successive positive and negative displacement ductility peaks. The maximum compressive strains in the core concrete were calculated for the gauge lengths shown (see the side elevation of the test units in Fig. 7) by linear interpolation of the longitudinal strains measured by each pair of linear potentiometers at a given level. Note that the concrete core is considered to commence at $23 \mathrm{~mm}$ from the outside face of the column, which is at the centre line of the perimeter hoops. The average compressive strain values were plotted at the midpoint of the gauge length and joined by straight lines. The side elevation of the test units in Fig. 7 show the location of the small steel hoops which were strain gauged to measure the transverse tensile strains in the column flanges. These gauges were designated either Eor $W$ for determining the hoop strains at positive and negative displacement peaks, respectively. The strain gauge results have been plotted and joined by straight lines.

Constant visual examination of the specimens during the early stages of testing enabled the strain at which spalling of the cover concrete first occurred to be identified. Spalling first occurred in the $80 \mathrm{~mm}$ gauge length at the bottom of the hollow column. The average concrete compressive strain in the extreme compression fibre was calculated from the linear potentiometer readings and is tabulated in Table 3. The minimum spalling strain was 0.008 , which is well in excess of the value of 0.003 generally used for ultimate strength calculations, and also in excess of 0.004 , often assumed in many momentcurvature analyses.

Table 3 also lists the maximum concrete compression strain found in the first or second gauge length at the edge of the confined concrete core, either at the end of quasi-static testing (Columns $A$ and $B$ ) or just prior to first hoop fracture (Columns $C$ and $D$ ). Also listed for comparison is the predicted maximum strain given by the following empirical expression suggested by Scott, Park and Priestley (5) $\varepsilon_{\max }=0.004+0.9 \rho_{s}\left(\frac{f_{y h}}{300}\right)$

Eq. 8 is based on the results of concentric axial compression tests on near full size square columns with overlapping hoops. It will be noted from Table 3 that this empirical expression gave a conservative estimate of the maximum strain obtained in the present test series.

The test results in Fig. 7 show that the compressive strain in the concrete core increased as the specimen curvature increased towards the base of the column. The compressive concrete strain in turn caused a lateral expansion of the concrete, inducing tensile strains in the hoop reinforcement. Yielding of the transverse hoops in the column flanges did not occur in Column $A$ due to the low level of axial load. Premature failure outside the fully confined zone of Column $B$, which had high levels of both confinement and axial load, also precluded the compressive strains from becoming large enough to cause yielding of the transverse hoops in the fully confined zone. However, yielding did occur in the transverse hoops of Columns $C$ and D, typically commencing at $\mu= \pm 4$. At higher levels of ductility the confining action was adequately maintained by the yielding hoops. First hoop fracture occurred in the flanges of Column $C$ in the second cycle at $\mu= \pm 8$, and at $\mu=-6.5$ and $\mu=+6$ for collumn D. The integrity of the core concrete was not maintained after hoop fracture occurred. The resulting loss of confinement and load carrying capacity of the column flanges subsequently led to a rapid deterioration in the lateral load strength of the test units.

It might be expected that the large compressive axial strains near the bottom of the hollow column would in turn cause yielding of the transverse flange hoops. However, Fig. 7 indicates that the strains in the flange hoops reduce markedly towards the bottom of the column. It is evident that the stiff solid concrete base of the test unit provided a confining effect to the column concrete immediately above the base. Thus it may be inferred that the confining stresses induced by the solid column base can exceed those provided by the hoop reinforcement. Consequently the critical section of the test unit appeared to be about $150 \mathrm{~mm}$ above the solid base.

Web Strains: Profiles of transverse strain measured in the long transverse web hoops at displacement ductility peaks are presented in Fig. 8. Yielding of these transverse hoops did not occur in any of the specimens during testing. This result was expected, since the specimens were detailed to resist a shear force in excess of that associated with the overstrength in flexure, in accordance with the capacity design procedure (1). The transverse strain measured in the long web hoops progressively increased in magnitude with both cyclic loading and successive increments of displacement ductility factor. It is evident that the strains induced in the web hoops were due to (a) some confinement of the 

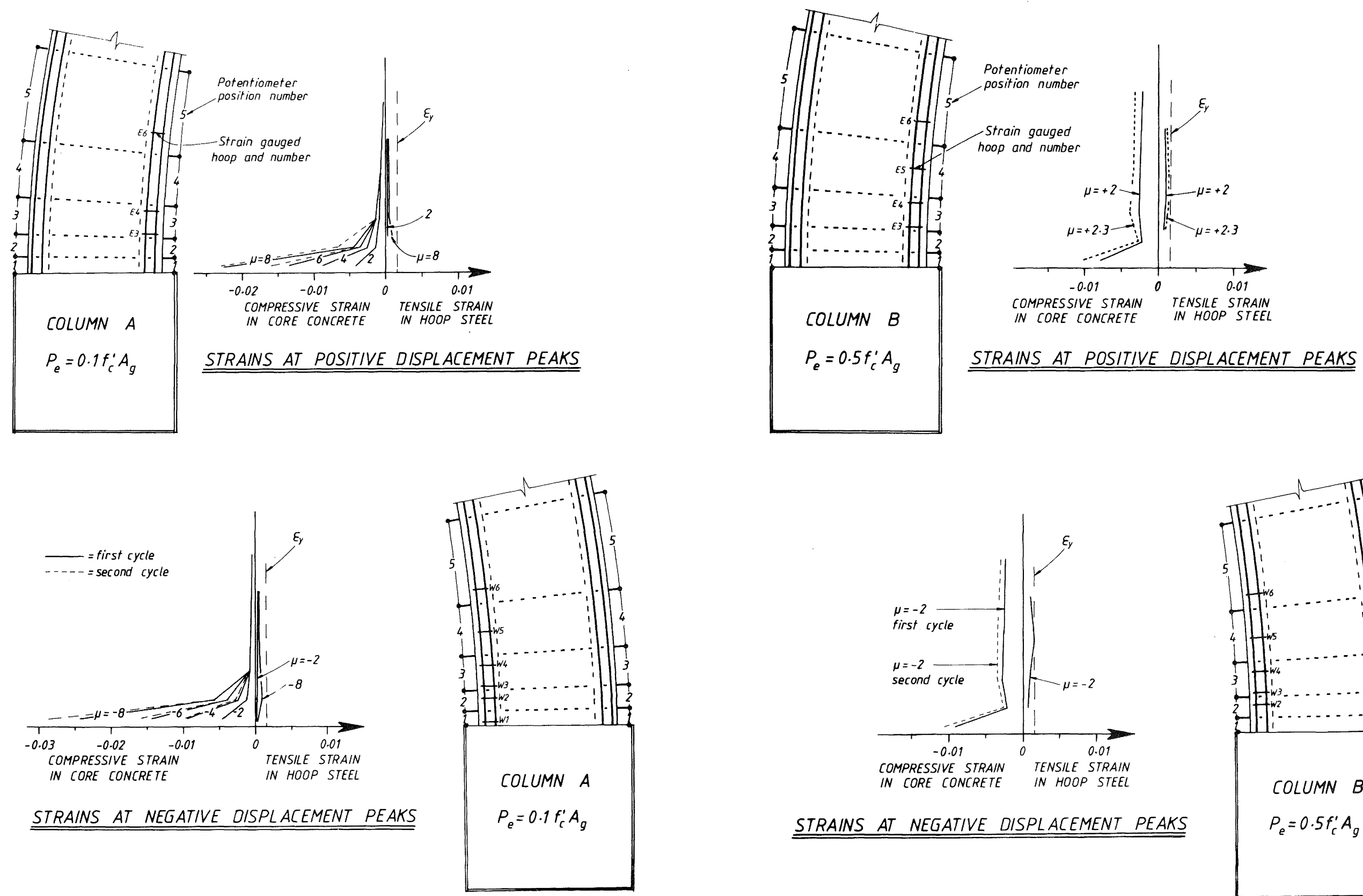

STRAINS AT NEGATIVE DISPLACEMENT PEAKS

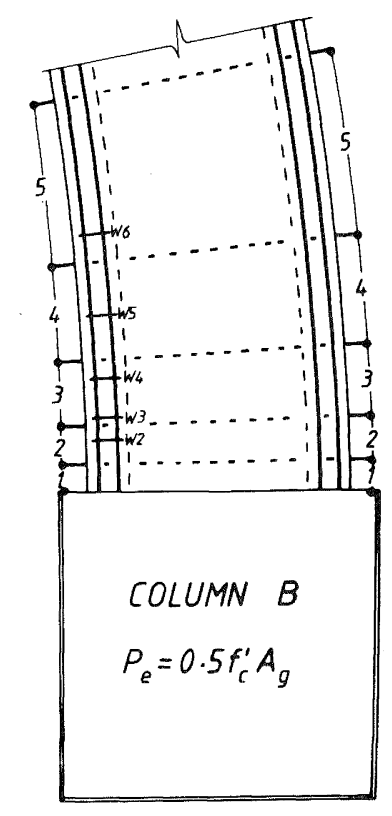

FIG. 7 : MEASURED LONGITUDINAL STRAINS IN CORE CONCRETE AND TRANSVERSE TENSILE STRAINS IN FLANGE HOOPS. 

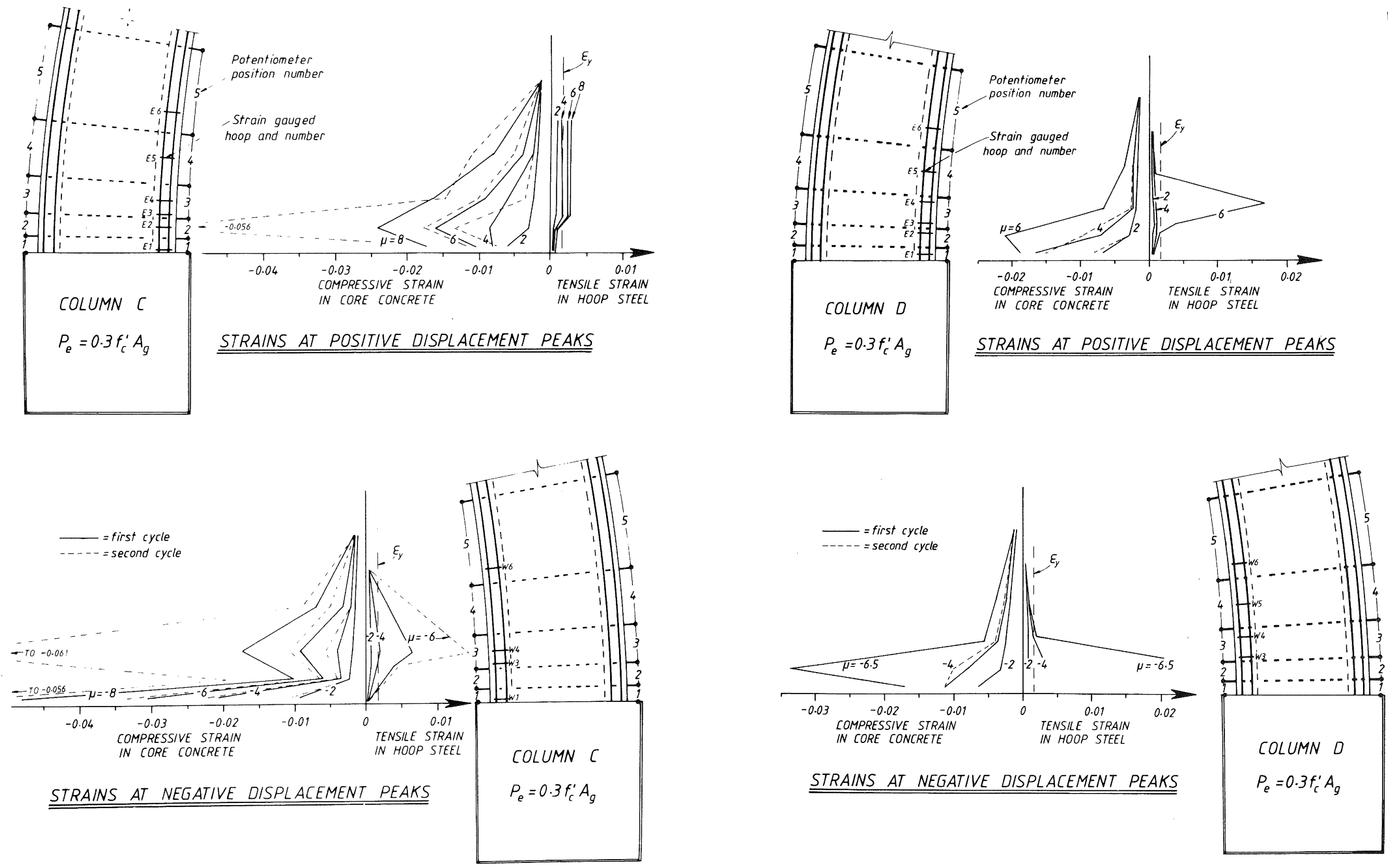

FIG. 7 (CTD) : MEESURED LONGITUDINAL STRAINS IN CORE CONCRETE AND TRANSIERSE TENSILE STRAINS IN TLANGE HOORS. 
compressed concrete core at the edges of the column flanges, (b) restraint of the longitudinal bars from buckling in the compression zone, and (c) resistance of some of the shear force in the section.

An examination of Fig. 8 reveals that at low levels of displacement ductility (typically $\mu=+2$ ) the shear carried by the steel was small. Despite the approximately constant level of lateral load, the shear force carried by the steel increased as the ductility factor increased. Hence a deterioration of the shear carried by the concrete occurred due to cyclic loading. It should be noted that the seismic design of column members requires the ideal shear capacity to exceed the shear generated at flexural overstrength (1). Thus, the provided shear strength will normally exceed the design shear forces by at least $40 \%$.

The ideal shear force carried by the transverse web hoops, $V$, can be calculated, assuming that cracks form at 45 degrees to the member axes and that the hoops yield, from the expression

$\mathrm{V}_{\mathrm{s}}=\mathrm{A}_{\mathrm{V}} \mathrm{f}_{\mathrm{yh}} \mathrm{d} / \mathrm{s}$

where $A_{y}$ is the area of transverse hoop reinforcement resisting shear, $f_{y h}$ is the yield stress of the web steel, $d$ is the effective depth of the member (assumed to be the distance from the extreme compression fibre to the centroid of the longitudinal reinforcement in the tension flange), and $s$ is the centre-to-centre spacing of the transverse shear reinforcement. The additional ideal shear force which can be carried by the concrete, $\mathrm{V}_{\mathrm{C}^{\prime}}$ can be calculated from the code (I) equation

$v_{C}=v_{C} b_{w} d$

in which $b_{w}$ is the total web width of the hollow column, $d$ is the effective depth of the member as defined above, and $v_{c}$

is the ideal shear stress provided by the concrete. According to NZS 3101 the ideal shear stress carried by the concrete in potential plastic hinge regions is given by

$v_{c}=4 \sqrt[v]{\frac{P_{e}}{f_{c^{\prime} g}^{A}}-0.1}$

but $\mathrm{V}_{\mathrm{C}}$ is taken as zero if $\mathrm{P}_{\mathrm{e}}$ produces an average axial stress less than $0.1 \mathrm{f}_{\mathrm{C}}^{\prime}$ The basic shear stress $v_{b}$ is given by

$v_{b}=\left(0.07+10 \rho_{w}\right) \sqrt{f_{c}^{\prime}}$

where $\rho_{w}$ is the ratio of the longitudinal reinforcement in the web to the web area only. The value of $\mathrm{v}_{\mathrm{b}}$, should be not more than $0.2 \sqrt{f_{C}^{\prime}}$, nor need be taken less than $0.08 \sqrt{f_{C}^{\prime}}$ where $f_{C}^{\prime}$ is in MPa units. Outside the potential plastic hinge region the ideal shear stress of the concrete is taken to be

$v_{c}=\left(1+\frac{3 P_{e}}{f_{c} A_{g}}\right) v_{b}$

where $\mathrm{v}_{\mathrm{b}}$ is defined in Eq. 12 .

The maximum applied shear forces measured during the tests together with the ideal shear strengths, $V_{s}$ and $V_{C^{\prime}}$ ' given by Eqs. $9-13$ are listed in Table 4. Comparison of the maximum applied shear forces indicates that in the plastic hinge regions $V_{S}$ alone was sufficient to carry all the shear. Thus little shear distress was observed and yielding of the web hoops did not occur (Fig. 8) as expected.

Outside the plastic hinge regions all units had adequate shear strength according to the maximum measured shear forces and Eqs. 9 - 13. However, the maximum shear carried by each specimen exceeded the ideal strength of the web steel, $V_{s}$. The absence of yielding of the web steel indicates the contribution of the concrete in resisting shear was significant.

\section{CONCLUSIONS :}

From the results of the four hollow column reinforced concrete specimens tested in this series the following conclusions are listed:

1. It appears reasonable to use the New Zealand Concrete Design Code (1) to detail the flanges of hollow columns by applying the transverse reinforcement provisions in the same manner as for solid column members when "full

ductility" (i.e. a structure displacement ductility factor $\mu$ of 6 ) is required. The tests indicated that the full quantity of hoop steel recommended by the code may be excessive if only limited ductility $(\mu<6)$ is required. The use of a reduced quantity of confining reinforcement when only limited ductility is required appears justified. Nonetheless it is important to ensure that at least antibuckling hoops are provided (i.e. the hoop spacing should not exceed six longitudinal bar diameters) and the length of the confined concrete is increased by $50 \%$ for columns with high levels of axial load $\left(\mathrm{P}>0.3 \mathrm{f} \mathrm{A}_{\mathrm{g}}\right)$, as required by the code (I).

2. The hysteretic performance of the hollow columns tested herein demonstrated very good energy dissipation characteristics. Little sign of strength degradation was shown prior to column failure by the fracturing of the transverse hoops in the flanges. The flexural capacity of the hollow columns exceeded the ideal strength (calculated using the measured unconfined concrete strength, the measured steel yield strength, and an ultimate compression 

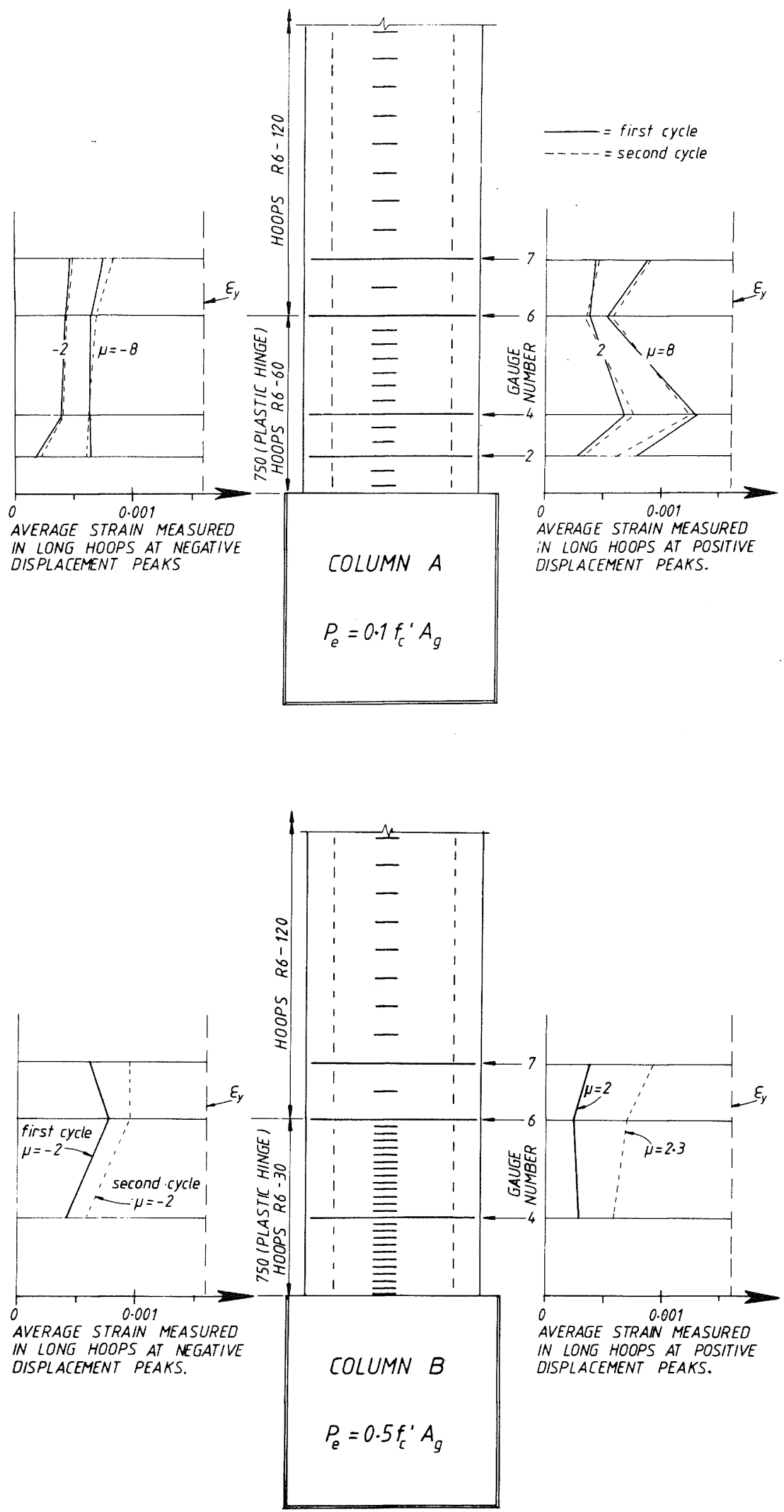
strain of 0.003 ) by up to $15 \%$ for the columns with low and medium axial loads, and up to $38 \%$ for the column with the high level of axial load. The large flexural capacity measured for the latter specimen was due to the significant increase in concrete strength as a result of the confinement from the hoop steel.

3. The test specimens demonstrated that well confined hollow reinforced concrete columns are capable of sustaining substantial plastic hinge rotations. For the purposes of ductility calculations it appears that the equivalent plastic hinge length for hollow columns with a height to depth aspect ratio of about four can be taken as $40 \%$ of the column depth. This compares reasonably well with an average value of $50 \%$ of the column depth suggested for solid columns (6).

4. After the concrete cover had spalled, and just prior to first hoop fracture, concrete compressive strains of between 0.028 and 0.050 were reached at the extreme compression fibre of the confined core. These experimental strains were typically $25 \%$ greater than the maximum compressive strains obtained using a proposed equation based on concentric axial compression test results.

5. The available plastic rotation of $\theta_{p}$ could be taken as

$$
\theta_{p}=0.035 \AA_{\text {radians }} \text { (provided) } / A_{\text {sh }} \text { (code) }
$$

\section{ACKNOWLEDGEMENTS :}

Financial assistance of the National Roads Board, the New Zealand Railways Corporation and the University of Canterbury is gratefully acknowledged. This research was part of a Ph.D. project by J.B. Mander supervised by M.J.N. Priestley and R. Park.

\section{REFERENCES :}

1. NZS 3101, "The Design of Concrete Structures", Part 1: Code of Practice, Part 2: Commentary, Standards Association of New Zealand, Wellington, New Zealand, 1982.

2. Mander J.B., "Seismic Design of Bridge Piers", Doctor of Philosophy Thesis in Preparation, University of Canterbury, Christchurch, New Zealand.

3. "Papers Resulting from Deliberations of the Society's Discussion Group on the Seismic Design of Bridges", Bulletin of the New Zealand National Society for Earthquake Engineering, Vo1. 13, No. 3, Septamber 1980, pp. 226-307.
5. Scott, B.D., Park, R., and Priestley, M.J.N., "Stress-Strain Behaviour of Confined Concrete by Overlapping Hoops at Low and High Strain Rates", Journal of the American Concrete Institute, January - February 1982, pp. 13-27.

6. Ang, B.G.,"Ductility of Reinforced Concrete Bridge Piers Under Seismic Loading", Master of Engineering Report, University of Canterbury, Christchurch, New Zealand, February 1981, 109 pp.
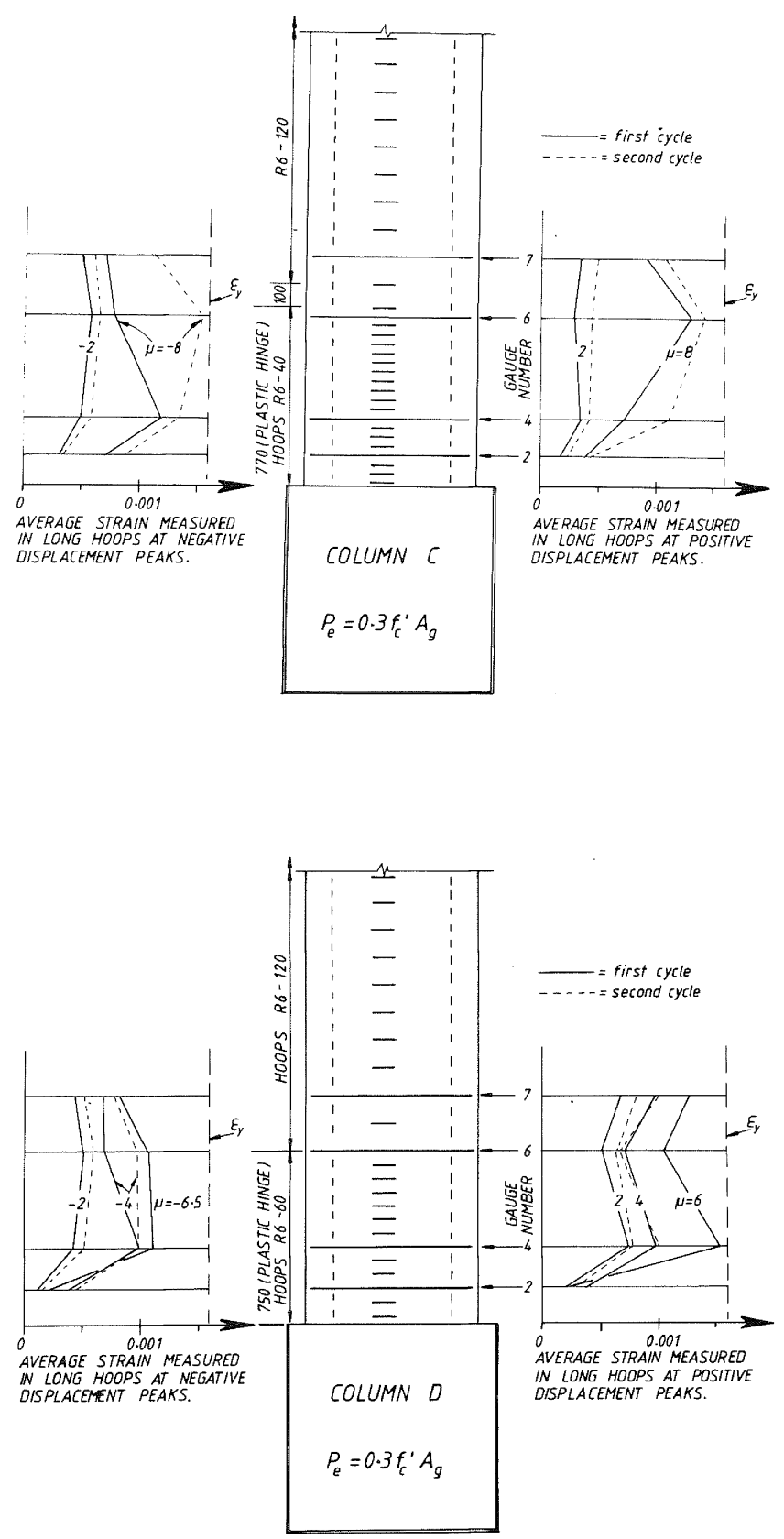

4. "Highway Bridge Design Brief" Ministry of Works and Development, New Zealand, CDP 701/D, September $1978,52 \mathrm{pp}$. 
TABLE 1 : EXPERIMENTAL EQUIVALENT PLASTIC HINGE LENGTHS

\begin{tabular}{|c|c|c|c|c|c|c|c|c|c|c|c|}
\hline \multirow[b]{2}{*}{ Column } & \multirow{2}{*}{$\frac{\mathrm{P}_{e}}{\mathrm{f}_{\mathrm{C}^{\prime} \mathrm{A}}}$} & \multirow{2}{*}{$\underset{(\mathrm{mm})}{\Delta_{\mathrm{y}}}$} & \multirow{2}{*}{ 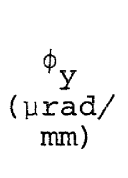 } & \multicolumn{2}{|c|}{$\mu=2$} & \multicolumn{2}{|c|}{$\mu=4$} & \multicolumn{2}{|c|}{$\mu=6$} & \multicolumn{2}{|c|}{$\mu=8$} \\
\hline & & & & $\frac{\phi_{\mathrm{u}}}{\phi_{\mathrm{y}}}$ & $\frac{L_{p}}{h}$ & $\frac{\phi_{\mathrm{u}}}{\phi_{\mathrm{y}}}$ & $\frac{L_{p}}{h}$ & $\frac{\phi_{\mathrm{u}}}{\phi_{\mathrm{y}}}$ & $\frac{\mathrm{L}_{\mathrm{p}}}{\mathrm{h}}$ & $\frac{\phi_{\mathrm{u}}}{\phi_{\mathrm{Y}}}$ & $\frac{L_{p}}{h}$ \\
\hline A & 0.1 & 14 & 4.16 & 7.9 & 0.21 & 12.3 & 0.39 & 19.6 & 0.40 & 28.7 & 0.37 \\
\hline B & 0.5 & 11 & 2.94 & 5.3 & 0.38 & & & & & & \\
\hline C & 0.3 & 13 & 4.64 & 6.5 & 0.22 & 10.6 & 0.38 & 16.2 & 0.40 & 22.4 & 0.40 \\
\hline D & 0.3 & 13 & 4.64 & 6.1 & 0.24 & 11.2 & 0.36 & 16.1 & 0.41 & - & - \\
\hline
\end{tabular}

TABLE 2 : EXPERIMENTAL AND PREDICTED DUCTILITY CAPACITY

\begin{tabular}{|c|c|c|c|c|c|}
\hline Column & $\frac{\mathrm{A}_{\mathrm{sh}} \text { (provided) }}{\mathrm{A}_{\mathrm{Sh}}(\text { code })}$ & $\mu(\exp t)$ & $\begin{array}{c}\mu(\text { predicted }) \\
\text { Eq. } 3\end{array}$ & 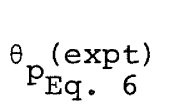 & $\begin{array}{c}\theta_{\mathrm{p}}(\text { predicted }) \\
\text { Eq. } 7\end{array}$ \\
\hline A & 0.74 & $8+$ & 6.4 & $0.032+$ & 0.026 \\
\hline B & 0.83 & $4^{*}$ & 7.0 & $0.011 *$ & 0.029 \\
\hline C & 0.83 & 6 & 7.0 & 0.030 & 0.029 \\
\hline D & 0.55 & 8 & 5.3 & 0.021 & 0.019 \\
\hline
\end{tabular}

+ test did not obtain a failure

* premature failure outside hinge region

TABLE 3 : EXPERIMENTAL FLANGE STRAINS

\begin{tabular}{|c|c|r|r|r|r|}
\hline & $\frac{\mathrm{P}_{\mathrm{e}}}{\mathrm{f}_{\mathrm{C}}^{\prime} \mathrm{A}_{\mathrm{g}}}$ & $\begin{array}{c}\text { Spalling } \\
\text { Strain }\end{array}$ & $\begin{array}{c}\text { Max. Core } \\
\text { Strain }\end{array}$ & $\rho_{\mathrm{S}}$ & $\begin{array}{c}\varepsilon_{\max } \\
\mathrm{Eq} \cdot 7\end{array}$ \\
\hline $\mathrm{A}$ & 0.1 & 0.008 & 0.029 & 0.0208 & 0.024 \\
$\mathrm{~B}$ & 0.5 & 0.008 & 0.010 & 0.0415 & 0.044 \\
$\mathrm{C}$ & 0.3 & 0.009 & 0.050 & 0.0312 & 0.034 \\
$\mathrm{D}$ & 0.3 & 0.009 & 0.028 & 0.0208 & 0.024 \\
\hline
\end{tabular}

* maximum core strain determined prior to first hoop fracture

TABLE $4:$ SHEAR STRENGTHS IN KILONEWTONS

\begin{tabular}{|c|c|c|c|c|c|c|c|c|c|}
\hline \multirow{2}{*}{ Column } & \multirow{2}{*}{$\frac{P_{e}}{f_{c}^{\prime} A_{g}}$} & \multirow{2}{*}{$\begin{array}{c}\mathrm{V}_{\max } \\
\text { (expt) }\end{array}$} & \multicolumn{3}{|c|}{ Plastic hinge region } & \multicolumn{4}{|c|}{ Outside hinge region } \\
\hline & & & $\mathrm{Eq} \cdot \mathrm{v}_{\mathrm{s}} 9$ & ${ }_{\mathrm{Eq}}{ }_{\mathrm{C}}{ }^{\mathrm{V}} 11$ & $v_{s}+v_{c}$ & Eq. ${ }^{\mathrm{V}_{\mathrm{s}}} 9$ & Eq. ${ }^{\mathrm{V}_{\mathrm{C}}}{ }_{13}$ & $\mathrm{v}_{\mathrm{s}}+$ & $+v_{c}$ \\
\hline A & 0.1 & 282 & 433 & 0 & 433 & 217 & 246 & & 463 \\
\hline B & 0.5 & 496 & 867 & 477 & 1344 & 217 & 472 & & 689 \\
\hline$C$ & 0.3 & 415 & 650 & 332 & 982 & 217 & 353 & & 570 \\
\hline D & 0.3 & 418 & 433 & 332 & 762 & 217 & 353 & & 570 \\
\hline
\end{tabular}

